\title{
INFLUENCE OF PREY AVAILABILITY AND INDUCED HOST-PLANT RESISTANCE ON OMNIVORY BY WESTERN FLOWER THRIPS
}

\author{
Anurag A. Agrawal, ${ }^{1}$ Chris Kobayashi, ${ }^{2}$ And Jennifer S. Thaler \\ Department of Entomology and Center for Population Biology, University of California-Davis, \\ One Shields Avenue, Davis, California 95616-8584 USA
}

\begin{abstract}
Theory predicts that the balance of nutritional needs, food availability, and the quality of particular food items are important factors in the feeding decisions of omnivorous animals. In this study we investigate factors that affect the feeding decisions of an omnivorous thrips (Frankliniella occidentalis) that eats both animal prey and plant foliage. In the presence of prey (mite eggs), adult and larval thrips consumed nearly half the amount of plant tissue as did thrips without prey. We manipulated host-plant quality by exposing plants to spider mite feeding. In the absence of prey, systemically induced plant responses following herbivory reduced the amount of feeding by thrips compared to that on uninduced control plants. In the presence of prey, induced responses caused a shift in the feeding preferences of thrips: thrips consumed half the amount of plant material and twice the number of prey on induced plants as did thrips on uninduced control plants. Our findings are relevant to understanding the complex factors that shape food-web interactions in nature. Variation in host-plant quality and availability of prey can exert a strong influence on the feeding preferences of omnivores. In addition, induced resistance may be a particularly useful biological-control strategy because it reduces herbivorous pest populations directly, and indirectly by causing a shift toward predation in naturally occurring omnivores.

Key words: biological control; cotton; Frankliniella; Gossypium; herbivory; induced plant resistance and omnivory; omnivore diet choices; omnivory and prey availability; plant-insect interactions; Tetranychus; thrips.
\end{abstract}

\section{INTRODUCTION}

Omnivory is considered a common feature of natural and managed communities (Polis et al. 1989, Polis 1991, Rosenheim et al. 1995, Naranjo and Gibson 1996, Polis and Winemiller 1996). Surprisingly, we have little information on how omnivores decide which food groups to consume. Theory and some evidence suggests that alternative food items have differential nutritional values for omnivores, and that feeding on more than one trophic level may act to balance an omnivore's diet (Schoener 1971, Westoby 1978, McMurtry and Rodriguez 1987, Bazely 1989, Polis et al. 1989, Bjorndal 1991). Evidence from omnivorous thrips, heteroptera, and phytoseiid mites suggests that the fitness of omnivores may be strongly affected by the quality and availability of various plant tissues and prey items (McMurtry and Rodriguez 1987, Trichilo and Leigh 1988, Alomar and Wiedenmann 1996, Coll 1996, McMurtry and Croft 1997, Milne and Walter 1997). In addition, the seasonal or local availability of food and the quality of food items may also influence feeding choices of omnivores. The complexity of food choice by omnivores is poorly understood. In partic-

Manuscript received 20 February 1998; revised 18 April 1998; accepted 13 May 1998.

${ }^{1}$ E-mail: aaagrawal@ucdavis.edu

${ }^{2}$ Present address: 3840 Carlson Road, Yuba City, California 95993 USA. ular, it is unknown if omnivores mix their diets primarily to fit nutritional needs or because they consume whichever high-quality food items are available (Westoby 1978).

Omnivores have often been implicated in the success of biological control (Wilson et al. 1991, Rosenheim et al. 1995, Alomar and Wiedenmann 1996, McMurtry and Croft 1997). In one study, enhancement of three omnivorous insects led to suppressed populations of herbivorous spider mites and increased reproduction of cotton plants (Agrawal and Karban 1997). On the other hand, plant feeding by omnivores can result in large negative effects for the plant. For example, flower thrips (Frankliniella spp.) are considered a serious pest in many systems (Robb and Parrella 1991, Grazia-Tommasini 1995), while in others they are important agents of biological control (Trichilo and Leigh 1986, Wilson et al. 1996, Agrawal and Karban 1997, Milne and Walter 1997). An important unanswered question is how omnivores make feeding decisions between plants and prey. Although variation in plant quality may affect plant feeding by omnivores (Trichilo and Leigh 1988, Coll 1996, Coll and Izraylevich 1997, De Kogel et al. 1997), previous studies have not manipulated intraspecific plant quality and investigated the effects on an omnivore's consumption of plants vs. prey.

Induction of plant resistance by herbivory is a source of intraspecific variation in plant quality that may be frequently encountered by plant-visiting arthropods. 


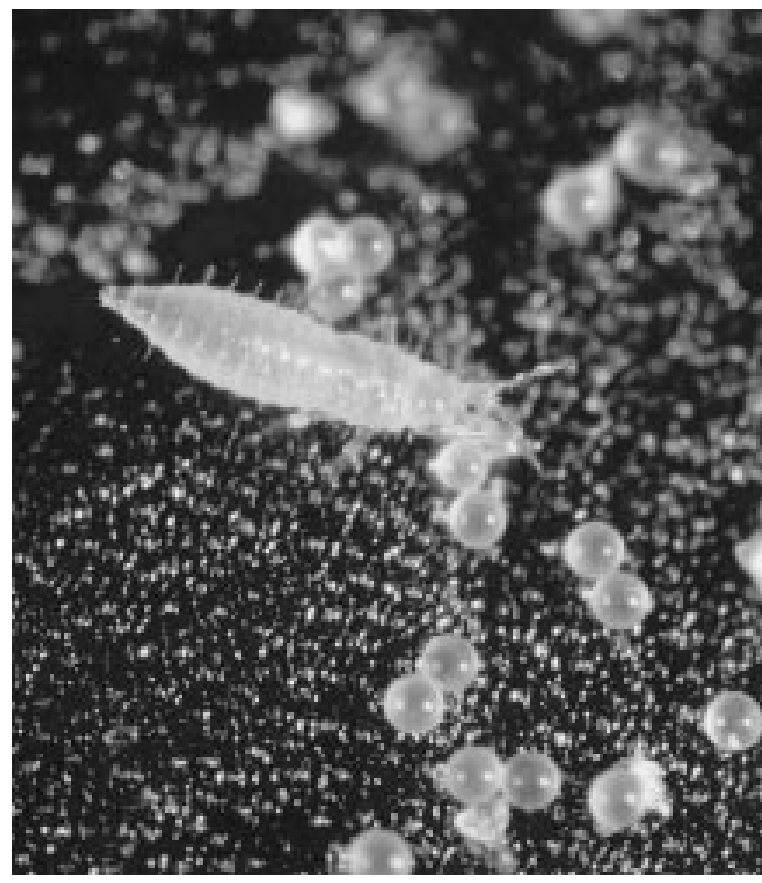

FIG. 1. Larval western flower thrips feeding on a spider mite egg on a cotton leaf. The thrips is $\sim 2 \mathrm{~mm}$ long. Photo courtesy of Jack Kelly Clark and the University of California Statewide IPM Project; printed with permission of the University of California.

Induced resistance to herbivores has been documented in over 100 plant-herbivore systems, and appears to be a common feature in a diverse array of plants (Karban and Baldwin 1997). The effects of induced resistance can be manifested as reduced performance and/ or preference of herbivores feeding on previously damaged plants. In the presence of high herbivore pressure, induced resistance can increases plant fitness compared to uninduced controls (Agrawal 1998). Omnivores may also be affected by induced plant responses to herbivory. We predict that where induced resistance reduces plant quality for omnivores, they will shift their feeding preferences from plant material to consume more prey items if they are available.

In this study we investigated how prey availability and induced plant responses to herbivory affect the feeding decisions of the omnivorous western flower thrips, Frankliniella occidentalis (Fig. 1). Specifically we asked the following questions: (1) In the presence of prey do thrips consume less plant material than in the absence of prey? (2) Do induced plant responses cause a reduction in the amount of plant feeding in the absence of prey? and (3) In the presence of prey, do induced responses cause a shift in the feeding preferences of thrips from plant material to prey?

\section{Materials AND Methods}

Cotton plants (Gossypium hirsutum var. Acala SJ-2) were grown in $125-\mathrm{mL}$ pots in greenhouse soil (U.C.
Mix [Redi Gro, Sacramento, California, USA]) in a growth chamber maintained at $27^{\circ} \mathrm{C}$ with a $16: 8$ light : dark cycle. Western flower thrips were obtained from a colony maintained on beans, and spider mite eggs were obtained from a colony of Tetranychus pacificus maintained on cotton seedlings. Spider mite eggs were collected using methods described in detail by Scriven and McMurtry (1971). In short, infested cotton seedlings were put in a water bath with a few drops of bleach to dissolve the mite webbing and release the mites into suspension. The water was then passed through a series of four mesh-lined containers. The mesh size sequentially decreased to catch leaves, adult mites, immature and male mites, and eggs, respectively. Eggs were transferred from the container and collected on filter paper by using a Buchner funnel.

\section{Omnivory in the absence of induced responses}

The first experiment was designed to test if the presence of prey affected the amount of plant feeding by thrips. In no-choice tests, we offered individual thrips one cotton cotyledon with or without five mite eggs placed on the cotyledon. The youngest (clear) eggs were chosen to minimize hatching during the experiment. On leaves with prey, each egg was transferred to a small area near the base of the leaf using a moistened fine paintbrush. Thrips were sealed with the leaf on moistened filter paper in a $90-\mathrm{mm}$-diameter petri dish and left for $3 \mathrm{~d}$. The cotyledons remained turgid and mite eggs did not hatch. We then counted the number of feeding scars left by the thrips. Each scar was defined as an $\sim 1 \mathrm{~mm}^{2}$ area of silvery tissue. Thrips feed on cell contents, and leaf damage was discrete and easily quantified using a dissecting microscope. The number of prey (mite eggs) consumed was also quantified on the treatment leaves with prey. This experiment was conducted four times, twice with first-instar thrips and twice with adult thrips ( $n=15$ samples for each treatment, each trial). The amount of plant feeding between treatment groups was compared using a twofactor analysis of variance with treatment (presence of prey) and trial as the main effects.

\section{Induced responses in the absence of prey}

The second experiment was designed to test if thrips were susceptible to induced host-plant changes caused by initial spider mite feeding. In California, thrips and spider mites often co-occur early in the season on young cotton plants (Agrawal and Karban 1997). Cotton plants were grown until the cotyledons had expanded and then they were randomly divided into two groups: (1) plant inoculated with 20-30 Tetranychus turkestani spider mites, or (2) undamaged control plants. In previous experiments, $T$. turkestani was found to be a potent inducer of resistance in young cotton plants (Karban and Carey 1984). After $3 \mathrm{~d}$ of feeding, all mites were killed using a non-systemic miticide (dicofol, Kelthane [Rohm and Haas, Philadel- 


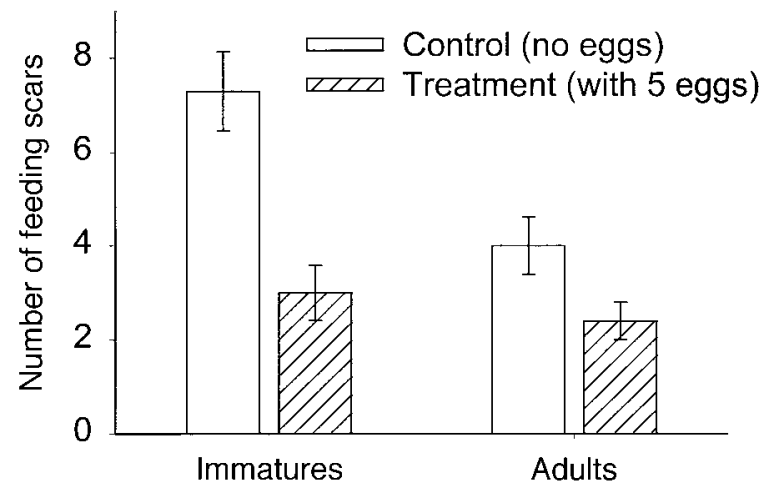

FIG. 2. Number of feeding scars left by western flower thrips on cotton cotyledons without prey or with five spider mite eggs in a no-choice experiment. First-instar and adult thrips were assayed. Data shown are means $\pm 1 \mathrm{SE}$.

phia, Pennsylvania, USA]). Plants treated with mites as well as controls were dipped in the miticide. At this stage, the first true leaf was only a bud. After 7-10 d of growth, when the first and second true leaves had expanded, the plants were fed to thrips. The first and second true leaf from each plant was excised using a razor blade and each leaf was placed in a petri dish on moistened filter paper. Leaves were inoculated with one first-instar thrips and the thrips were allowed to feed for $3 \mathrm{~d}$, after which time the number of feeding scars was quantified. If the thrips was missing or died without feeding, it was omitted from the analysis. This experiment was conducted twice with $n=12-17$ plants for each treatment, each trial.

Mortality of thrips on control and induced plants was compared using a chi-square test. The amount of feeding was compared using a two-factor multivariate analysis of variance (MANOVA), with treatment (induction) and trial as the factors, and number of feeding scars on leaf one and leaf two as the response variables. We employ the MANOVA approach because we collected thrips feeding data on two non-independent leaves of the same plants. Previous experiments (Karban and Thaler 1999) and ours (see Results) find that as cotton plants mature, subsequently formed true leaves are more resistant to herbivores than older true leaves. The second true leaf was not always fully expanded and was therefore not used; our replication was thus slightly reduced because MANOVA requires that all response-variable cells be filled for each sample.

\section{Induced responses and omnivory}

The goal of this experiment was to determine if induced plant responses would affect the feeding preferences of thrips when thrips were given a choice between plant tissue and prey. The setup of this experiment was identical to the experiments conducted on induced resistance in the absence of prey, except that all leaves were inoculated with five spider mite eggs. First-instar thrips were allowed to feed for 4 d, after which the feeding scars and the number of eggs consumed were quantified. This experiment was conducted twice with $n=17-26$ first and second true leaves for each treatment, each trial. We tested for effects of treatment (induction) and trial using a two-factor MANO$\mathrm{VA}$, with the number of feeding scars and the number of eggs consumed on the first and second true leaves as the response variables. Feeding scars and the number of eggs consumed were paired as response variables because they are not necessarily independent.

\section{RESUlts}

Prey availability affected leaf feeding by thrips. In the presence of prey (mite eggs), both adult and larval thrips consumed prey, but consumed nearly half the amount of plant tissue as they did on control leaves without prey (Fig. 2, Table 1). First-instar thrips consumed $0.40 \pm 0.13$ mite eggs (mean $\pm 1 \mathrm{SE}$ ) and adults consumed $1.6 \pm 0.29$ mites eggs in the treatment where they were available.

Induced resistance also affected performance of thrips and the amount of plant feeding vs. animal feeding that they exhibited. In the absence of prey, induced resistance nearly doubled the mortality of thrips from $24 \%$ on controls to $43 \%$ on induced plants $\left(\chi^{2}=3.865\right.$, $P<0.05)$. In addition, on leaves that received some damage, induced resistance significantly reduced the amount of plant feeding by $>30 \%$ on both the first and second true leaves in the absence of prey (Fig. 3, Table 2A). This effect was due to a combination of reduced tissue loss from both mortality of thrips and reduced per capita feeding. In the presence of prey, induced resistance caused a shift in the feeding preferences of the thrips (Fig. 4, Table 2B). Induction caused a near$50 \%$ reduction in plant feeding and a doubling of egg consumption by thrips compared to that on uninduced controls.

\section{DISCUSSION}

Western flower thrips are often found co-occurring with spider mites on young cotton plants in California, and on this crop it is believed that their role as predators of spider mites is far more important than as herbivores

TABLE 1. ANOVA results for the effects of presence of prey on (A) larval and (B) adult plant feeding by thrips.

\begin{tabular}{lrrrr}
\hline \hline Source of variation & df & \multicolumn{1}{c}{ MS } & \multicolumn{1}{c}{$F$} & \multicolumn{1}{c}{$P$} \\
\hline A) Larval & & & & \\
$\quad$ Treatment & 1 & 277.350 & 24.339 & $<0.001$ \\
$\quad$ Trial & 1 & 252.150 & 22.128 & $<0.001$ \\
$\quad$ Treatment $\times$ trial & 1 & 16.017 & 1.406 & 0.241 \\
$\quad$ Error & 56 & 11.476 & & \\
B) Adult & & & & \\
$\quad$ Treatment & 1 & 38.400 & 4.632 & 0.036 \\
$\quad$ Trial & 1 & $<0.001$ & $<0.001$ & 1.000 \\
$\quad$ Treatment $\times$ trial & 1 & $<0.001$ & $<0.001$ & 1.000 \\
$\quad$ Error & 56 & 8.144 & & \\
\hline
\end{tabular}




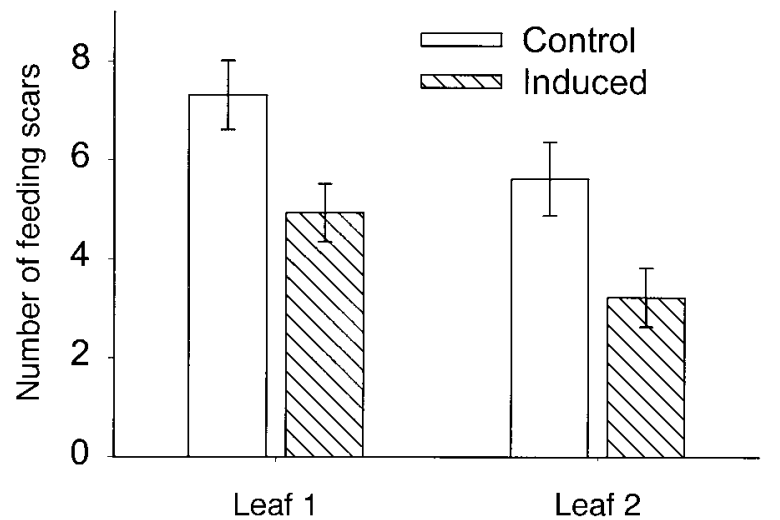

FIG. 3. Number of feeding scars left by western flower thrips on cotton leaves from control plants or from plants that were induced by exposure of the cotyledons to spider mites in a no-choice experiment. No prey were present in this experiment. The first and second true leaf from each plant was assayed. Data shown are means \pm 1 SE.

(Gonzalez and Wilson 1982, Trichilo and Leigh 1986, 1988, Wilson et al. 1991, Agrawal and Karban 1997). We have demonstrated that both availability of prey and plant quality can have consequences for feeding in this omnivorous thrips. In the presence of prey (mite eggs), thrips mixed their diet between prey and plant material. Because the thrips did not exclusively feed on prey or plant material when given a choice, our results are consistent with the hypothesis that omnivory helps to meet nutritional needs of animals.

We found that induced plant responses caused by spider mite feeding reduced the amount of plant feeding by thrips when prey were not available. To our knowledge this is the first report of the effect of induced responses on omnivores. It is unknown whether thrips feeding itself may induce resistance in plants. However, if it does, such induction may itself feed back to cause changes in the feeding preferences of the thrips.

We found that in the absence of prey, thrips mortality was higher on induced plants compared to that on controls. However, in the presence of prey, thrips experienced very little mortality on induced plants and they ate less plant material and more prey compared to that on uninduced plants. At this stage it is unclear if prey quality also changes on induced plants. Although spider mites are generally not thought to sequester plant secondary compounds, if induced phytochemicals are inside of mites passively, then predators may also be exposed to these compounds. Induction may reduce plant as well as prey quality, and the resulting effect on the feeding preferences of the omnivore are ambiguous.

In field experiments with cotton, we also found that induced responses following initial spider mite herbivory significantly reduced natural populations of thrips compared to those on control plants (A. A. Agrawal, R. Karban, and R. G. Colfer, unpublished manuscript).
TABLE 2. MANOVA results for the effects of induced resistance on (A) plant feeding by thrips in the absence of prey and on (B) plant feeding and prey consumption when both plants and prey were available.

\begin{tabular}{lcccc}
\hline \hline Source of variation & Wilks $\lambda$ & df & $F$ & $P$ \\
\hline A) Plant consumption & & & & \\
Treatment & 0.762 & 2,41 & 6.389 & 0.004 \\
Trial & 0.703 & 2,41 & 8.668 & 0.001 \\
Treatment $\times$ trial & 0.934 & 2,41 & 1.442 & 0.248 \\
B) Plant and prey consumption & & & \\
Treatment & 0.619 & 4,38 & 5.857 & 0.001 \\
Trial & 0.888 & 4,38 & 1.197 & 0.329 \\
Treatment $\times$ trial & 0.796 & 4,38 & 2.437 & 0.064 \\
\hline
\end{tabular}

Similarly, in tomato fields we found that induced resistance stimulated by application of the natural plant elicitor jasmonic acid reduced thrips populations compared to those on control plants that were not induced (J. S. Thaler, M. J. Stout, R. Karban, and S. S. Duffey, unpublished manuscript). In these experiments, it was not determined if induction caused thrips to leave induced plants or whether thrips experienced reduced fecundity and increased mortality. In addition, in the experiments with cotton plants, induction had a direct negative effect on spider mite populations; thus, we were unable to detect the effect of induction on prey consumption by thrips because induction was confounded with reduced prey availability (A. A. Agrawal, R. Karban, and R. G. Colfer, unpublished manuscript).

In addition to the direct effects of induction on multiple plant attackers (Karban and Carey 1984, Karban 1986, 1988, Karban et al. 1987, A. A. Agrawal, R. Karban, and R. G. Colfer, unpublished manuscript), there are also several potential indirect benefits of induction (Karban et al. 1997, Karban and Baldwin 1997, Agrawal and Karban 1998). For example, induced re-

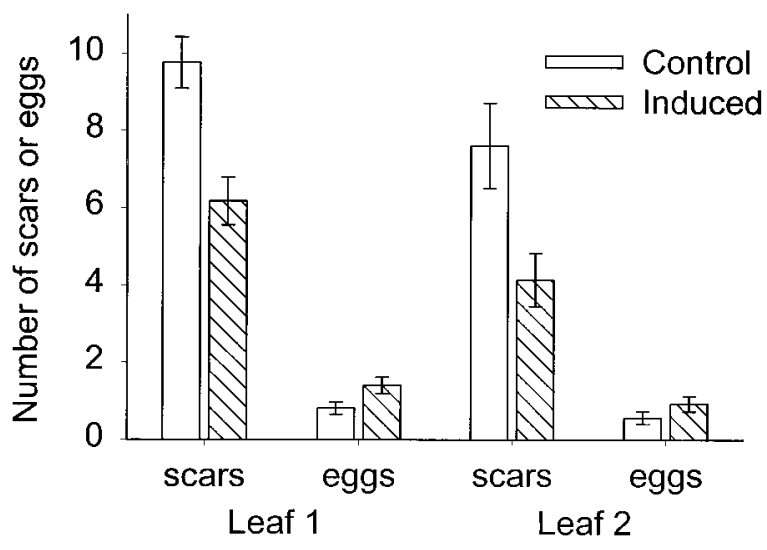

FIG. 4. Numbers of feeding scars and eggs consumed by western flower thrips on cotton leaves from control plants or from plants that were induced by exposure of the cotyledons to spider mites in a no-choice experiment. All leaves were inoculated with five spider mite eggs. The first and second true leaf from each plant was assayed. Data shown are means $\pm 1 \mathrm{SE}$. 
sponses may be beneficial to plants because they attract predators and parasites of herbivores in many systems including cotton (Drukker et al. 1995, Rose et al. 1996, Takabayashi and Dicke 1996, Shimoda et al. 1997). Induction may promote dispersed herbivory on plants, which could be less damaging than concentrated damage (Edwards and Wratten 1983, Marquis 1992, 1996). Our experiments demonstrate an additional novel benefit of induction: induced responses influenced an omnivorous thrips to prey on more spider mite eggs, while feeding less on the cotton leaves compared to thrips on uninduced control plants. In other words, induced responses to herbivory may not only reduce pest populations directly, but also indirectly by causing omnivores to increase predation. We predict that where induction of resistance reduces plant quality for omnivores they will shift their feeding preferences away from herbivory towards carnivory.

Many plant factors may influence the degree of omnivory. For example, pollen availability is often implicated in the success of phytoseiid mites as predators (McMurtry and Rodriguez 1987, McMurtry and Croft 1997). Gonzalez and Wilson (1982) observed that late in the growing season of cotton, thrips inhabited flowers and were less effective predators of spider mites. Pollen may be a better food source for thrips than leaves, and the availability of alternative foods and food quality may affect the late-season control of spider mites in this system. Eubanks and Denno (1997) have recently reported similar findings in an experimental system involving bean plants, several herbivores, and omnivorous big-eyed bugs (Geocoris spp.). In their studies, the availability of high-quality bean pods resulted in a shift away from predation by big-eyed bugs and a net increase in populations of their aphid prey. In our own experiments with big-eyed bugs on cotton, we did not find that decreased host-plant quality (induced resistance) affected bug populations (A. A. Agrawal, R. Karban, and R. G. Colfer, unpublished manuscript). This may be related to the fact the omnivorous bugs are primarily predaceous, feed minimally on phloem or xylem (Armer et al. 1998), and rely less on plant material than omnivores such as Frankliniella occidentalis. Alternatively, plant resources may be important for these omnivores, and they may or may not compensate for reduced plant quality by consuming more prey. Especially in cases where eggs of primarily predaceous omnivores, such as Orius spp., are laid in the plant tissue, induced resistance may have a strong negative impact on omnivores. Ultimately, the effects of plant and prey quality on omnivory will depend on the food requirements and sensitivity of the animals involved (see also Coll and Izraylevich [1997]). We believe this to be an exciting and important area of research for both community ecology and agroecology. At this stage, however, there are too few documented cases of variation in the feeding pref- erences of omnivores for different foods to generalize patterns.

Although the static qualities of plants and prey items will likely be a factor in feeding decisions of omnivores, intraspecific plant variation may exert a finer scale and potentially important influence on such feeding decisions. If induced plant resistance makes omnivores more likely to consume prey rather than plant material, biological control strategies that incorporate induced resistance could be synergistically enhanced by omnivores feeding on herbivorous pests. Omnivores are common and abundant components of the natural arthropod fauna of many systems. Manipulation of plant quality by induced resistance and other methods may be an excellent strategy not only to reduce plant feeding by omnivores, but also to increase their control of herbivorous pests. In natural systems where omnivores are also common, subtle differences in plant quality may determine the vertical and horizontal impact of omnivores in food webs.

\section{ACKNOWLEDGMENTS}

This study was primarily supported by the University of California, Davis-Young Scholars Program (C. Kobayashi). We thank Rick Pomeroy and Julie Oliver for administrative support. Previous versions of this manuscript were improved by the helpful comments of Rick Karban, Jay Rosenheim, Tom Schoener, Marcel Holyoak, Sharon Lawler, Lynn Adler, Emilio Bruna, Anthony Joern, and four anonymous reviewers. Chris Wardlaw maintained the mite colonies. Diane Ullman and her laboratory graciously donated the western flower thrips and gave us advice when needed. Financial support was provided by the defunct NSF Young Scholars Program and personal funds (C. Kobayashi), NSF Grant DEB-9701109 (A. A. Agrawal), and USDA Grant 9602065 (J. S. Thalor).

\section{Literature Cited}

Agrawal, A. A. 1998. Induced responses to herbivory and increased plant performance. Science 279:1201-1202.

Agrawal, A. A., and R. Karban. 1997. Domatia mediate plant-arthropod mutualism. Nature 387:562-563.

Agrawal, A. A., and R. Karban. 1998. Why induced defenses may be favored over constitutive strategies in plants. Pages 45-61 in R. Tollrian and D. Harvell, editors. Ecology and evolution of inducible defenses. Princeton University Press, Princeton, New Jersey, USA.

Alomar, O., and R. N. Wiedenmann. 1996. Zoophytopagous Heteroptera: implications for life history and integrated pest management. Entomological Society of America, Lanham, Maryland, USA.

Armer, C. A., R. N. Wiedenmann, and D. R. Bush. 1998. Plant feeding site selection on soybean by the facultatively phytophagous predator Orius insidiosus. Entomologia Experimentalis et Applicata 86:109-118.

Bazely, D. R. 1989. Carnivorous herbivores: mineral nutrition and the balanced diet. Trends in Ecology and Evolution 4:155-156.

Bjorndal, K. A. 1991. Diet mixing: nonadditive interactions of diet items in an omnivorous freshwater turtle. Ecology 72:1234-1241.

Coll, M. 1996. Feeding and ovipositing on plants by an omnivorous insect predator. Oecologia 105:214-220.

Coll, M., and S. Izraylevich. 1997. When predators also feed on plants: effects of competition and plant quality on omnivore-prey population dynamics. Annals of the Entomological Society of America 90:155-161. 
De Kogel, W., M. Van Der Hoek, and C. Mollema. 1997. Variation in performance of western flower thrips populations on susceptible and partially resistant cucumber. Entomologia Experimentalis et Applicata 83:73-80.

Drukker, B., P. Scutareanu, and M. W. Sabelis. 1995. Do anthocorid predators respond to synomones from Psyllainfested pear trees under field conditions? Entomologia Experimentalis et Applicata 77:193-203.

Edwards, P. J., and S. D. Wratten. 1983. Wound induced defences in plants and their consequences for patterns of insect grazing. Oecologia 59:88-93.

Eubanks, M. D., and R. F. Denno. 1997. The effects of plant quality and alternative prey on the suppression of aphid populations by an omnivore. Bulletin of the Ecological Society of America 78(4):85.

Gonzalez, D., and L. T. Wilson. 1982. A food-web approach to economic thresholds: a sequence of pests/predaceou arthropods on California cotton. Entomophaga 27:s31-s43.

Grazia-Tommasini, M. 1995. Frankliniella occidentalis and other thrips harmful to vegetable and ornamental crops in Europe. Pages 1-42 in A. J. M. Loomans, J. C. van Lenteren, M. G. Tommasini, S. Maini, and J. Riudavets, editors. Biological control of thrips pests. Wageningen Agricultural University, Wageningen, The Netherlands.

Karban, R. 1986. Induced resistance against spider mites in cotton: field verification. Entomologia Experimentalis et Applicata 42:239-242.

. 1988. Resistance to beet army worms (Spodoptera exigua) induced by exposure to spider mites (Tetranychus turkestani) in cotton. American Midland Naturalist 119:7782.

Karban, R., R. Adamchak, and W. C. Schnathorst. 1987. Induced resistance and interspecific competition between spider mites and a vascular wilt fungus. Science 235:678-680.

Karban, R., A. A. Agrawal, and M. Mangel. 1997. The benefits of induced defenses against herbivores. Ecology $\mathbf{7 8}$ : $1351-1355$.

Karban, R., and I. T. Baldwin. 1997. Induced responses to herbivory. University of Chicago Press, Chicago, Illinois, USA.

Karban, R., and J. R. Carey. 1984. Induced resistance of cotton seedlings to mites. Science 225:53-54.

Karban, R., and J. S. Thaler. 1999. Plant phase change and resistance to herbivory. Ecology 80:510-517.

Marquis, R. J. 1992. A bite is a bite is a bite? Constraints on response to folivory in Piper arieianum (Piperaceae). Ecology 73:143-152.

. 1996. Plant architecture, sectoriality and plant tolerance to herbivores. Vegetatio 127:85-97.

McMurtry, J. A., and B. A. Croft. 1997. Life-styles of phytoseiid mites and their roles in biological control. Annual Review of Entomology 42:291-321.

McMurtry, J. A., and J. G. Rodriguez. 1987. Nutritional ecology of Phytoseiid mites. Pages 609-644 in F. Slansky and J. G. Rodriguez, editors. Nutritional ecology of insects, mites, and spiders. John Wiley \& Sons, New York, New York, USA.

Milne, M., and G. H. Walter. 1997. The significance of prey in the diet of the phytophagous thrips, Frankliniella schultzei. Ecological Entomology 22:74-81.

Naranjo, S. E., and R. L. Gibson. 1996. Phytophagy in pre- daceous heteroptera: effects on life history and population dynamics. Pages 57-92 in O. Alomar and R. N. Wiedenmann, editors. Zoophytopagous Heteroptera: implications for life history and integrated pest management. Entomological Society of America, Lanham, Maryland, USA.

Polis, G. A. 1991. Complex trophic interactions in desertsan empirical critique of food-web theory. American Naturalist 138: 123-155.

Polis, G. A., C. A. Myers, and R. D. Holt. 1989. The ecology and evolution of intraguild predation-potential competitors that eat each other. Annual Review of Ecology and Systematics 20:297-330.

Polis, G. A., and K. O. Winemiller. 1996. Food webs: integration of patterns and dynamics. Chapman \& Hall, New York, New York, USA.

Robb, K. L., and M. P. Parrella. 1991. Western flower thrips, a serious pest of floricultural crops. Pages 343-358 in B. L. Parker, M. Skinner, and T. Lewis, editors. Towards understanding the Thysanoptera. General Technical Report NE-147. U.S. Department of Agriculture, Forest Service, Radnor, Pennsylvania, USA.

Rose, U. S. R., A. Manukian, R. R. Heath, and J. H. Tumlinson. 1996. Volatile semiochemicals released from undamaged cotton leaves. Plant Physiology (Rockville) 111: 487-495.

Rosenheim, J. A., H. Kaya, L. E. Ehler, J. J. Marois, and B. A. Jaffee. 1995. Intraguild predation among biologicalcontrol agents: theory and evidence. Biological Control 5: 303-335.

Schoener, T. W. 1971. Theory of feeding strategies. Annual Review of Ecology and Systematics 2:369-404.

Scriven, G. T., and J. A. McMurtry. 1971. Quantitative production and processing of Tetranychid mites for large-scale testing or predator production. Journal of Economic Entomology 64:1255-1257.

Shimoda, T., J. Takabayashi, W. Ashihara, and A. Takafuji. 1997. Response of predatory insect Scolothrips takahashii toward herbivore-induced plant volatiles under laboratory and field conditions. Journal of Chemical Ecology 23: 2033-2048.

Takabayashi, J., and M. Dicke. 1996. Plant-carnivore mutualism through herbivore-induced carnivore attractants. Trends in Plant Science 1:109-113.

Trichilo, P. J., and T. F. Leigh. 1986. Predation on spider mite eggs by the western flower thrips, Frankliniella occidentalis (Thysanoptera: Thripidae), an opportunist in a cotton agroecosystem. Environmental Entomology 15:821825.

Trichilo, P. J., and T. F. Leigh. 1988. Influence of resource quality on the reproductive fitness of flower thrips (Thysanoptera: Thripidae). Annals of the Entomological Society of America 81:64-70.

Westoby, M. 1978. What are the biological bases of varied diets? American Naturalist 112:627-631.

Wilson, L. J., L. R. Bauer, and G. H. Walter. 1996. 'Phytophagous' thrips are facultative predators of two-spotted spider mites (Acari: Tetranychidae) on cotton in Australia. Bulletin of Entomological Research 86:297-305.

Wilson, L. T., P. J. Trichilo, and D. Gonzalez. 1991. Natural enemies of spider mites (Acari: Tetranychidae) on cotton: density regulation or casual association? Environmental Entomology 20:849-856. 